\title{
CHARACTERIZATION OF NANODISPERSED GRAPHITE
}

\author{
YU.S. PERETS,${ }^{1}$ I.V. OVSIIENKO,${ }^{1}$ L.L. VOVCHENKO,${ }^{1}$ L.YU. MATZUI, ${ }^{1}$ \\ O.A. BRUSILOVETZ, ${ }^{2}$ I.P. PUNDYK ${ }^{2}$
}

${ }^{1}$ Taras Shevchenko National University of Kyiv, Department of Physics

(64, Volodymyrska Str., Kyiv 01033, Ukraine; e-mail: peres20070 ya.ru)

PACS 81.07.-b

${ }^{2}$ Taras Shevchenko National University of Kyiv, Department of Chemistry

(C) 2012

(64, Volodymyrska Str., Kyiv 01033, Ukraine)

The work is devoted to the questions of interrelations between methods of functionalization and to the distribution character of functional groups on the surface of nanographite plates. The functionalization of initial thermoexfoliated graphite (TEG) is carried out with the use of inorganic reagents such as $\mathrm{KMnO}_{4}$ solutions in the sulfuric acid or a mixture of sulfuric and nitric acids and during different times of first and re-dispersion in a magnetic stirrer. The quantitative and qualitative compositions of functional groups on the surface of nanographite plates are determined by infrared spectroscopy method. As it is revealed from the detailed studies of a structure of functionalized graphite, the functionalization results in the destruction of the initial TEG structure and a reduction of the size of TEG particles down to several nanometers.

\section{Introduction}

Nanocarbon in all its forms (carbon nanotubes, nanographite, thermoexfoliated graphite (TEG)) does not form dispersions or solutions in organic solvents and water. Nanocarbon particles, including CNTs, are prone to the aggregation and the formation of bundles and matted nets due to the relatively strong van der Waals long-range interaction, which occurs between separate nanocarbon particles. However, the implementation of a stable homogeneous dispersion of particles in a polymer nanocarbon matrix is the most important issue in the creation of polymer composites with homogeneous structure $[1,2]$. One can use two ways to realize a uniform distribution of the nanocarbon component in a polymer matrix: mechanical and chemical processing methods [3,4]. The physical separation of nanocarbon particles is realized by a mechanical treatment. When nanocarbon interacts with some substances such as oxygen, fluorine, ozone, oxygen-containing acids, and salts, some functional groups join the nanocarbon surface [58]. Functional groups on the nanocarbon surface modify the surface properties, create conditions for the homogeneous distribution of a nanocarbon filler in the polymer matrix, and provide a strong bond between filler parti- cles and the polymer matrix [9-12]. The present work is devoted to the questions of interrelations between the methods of chemical covalent functionalization and the structure of functionalizated TEG [13].

\section{Experimental Technique}

Thermoexfoliated graphite has been produced by the thermochemical treatment of natural disperse graphite GAK 1 from Zavalie field used as a source material. Natural disperse graphite was intercalated to the first stage by sulfur acid according to the dichromate technology, and then it was thermally exfoliated in an ascending flow furnace at the temperature (1173-1273) K. TEG was flooded by the appropriate amount of a reagent according to the selected method. A $1.5 \mathrm{M}$ solution of potassium permanganate in $20 \%$ sulfur acid was used as a reagent in a case of method 1 . In a case of method 2 (with the boiling in a functionalizing agent) and method 3 (without boiling in functionalizing agent), the mixture of $96 \%$ sulfur acid and $65 \%$ nitric acid in a volumetric ratio 1:3 was used as a functionalizing agent. After the flooding of a TEG powder by an appropriate reagent, a mixture was formed, in which TEG particles were mainly floated on the surface of the liquid. A sand bath was used to heat the TEG-liquid mixture within methods 1 and 2. As a result of the first dispersing of this mixture in a magnetic mixer for $1 \mathrm{~h}$, the suspension, in which TEG particles were uniformly distributed in the liquid phase, was formed. After the impregnation of TEG by the reagent for $24 \mathrm{~h}$, TEG particles settle to the bottom of a flask. The repeated dispersing of the mixture in a magnetic mixer leads to a uniform distribution of TEG particle in the suspension. The particle size decreases, as the dispersing time increases. The quantitative and qualitative compositions of functional groups on the surface of TEG particles were determined by the infrared spectroscopy method. The experiments have been performed with a Perkin Elmer Spectrum BX FT-IR infrared spec- 


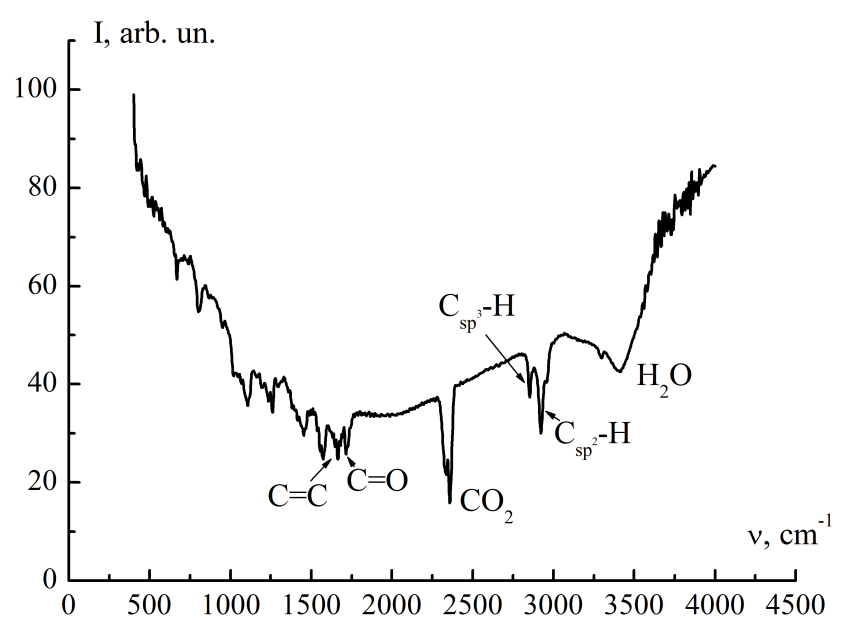

Fig. 1. The IR spectrum of the source TEG

trometer in the frequency range $4000-400 \mathrm{~cm}^{-1}$. The specimens in a form of pellets $10 \mathrm{~mm}$ in diameter were prepared from the powder mixture of TEG and $\mathrm{KBr}$. The structure of functionalizated TEG was investigated by the electron microscopy method. The investigations were performed using an electron microscope JEOL 200.

\section{Results and Discussion}

Figure 1 presents the IR absorption spectrum for the source TEG.

Evidently, the absorption spectrum for TEG contains a series of peaks and bands, two of which correspond to the impurities. Namely, a wide band at $3410 \mathrm{~cm}^{-1}$ corresponds to vibrations of the bounded $-\mathrm{OH}$ groups (water), and the intensive peak at $2354 \mathrm{~cm}^{-1}$ does to vibrations of carbon dioxide. A group of peaks near $3000 \mathrm{~cm}^{-1}$ in the IR spectrum of TEG is related to the valence $\mathrm{C}-\mathrm{H}$ vibrations. In addition, several peaks near $1600 \mathrm{~cm}^{-1}$ corresponding to the vibrations of $\mathrm{C}=\mathrm{C}$ and $\mathrm{C}=\mathrm{O}$ multiple bonds are also observed.

The IR absorption spectra for TEG functionalized with inorganic compounds are presented in Fig. 2.

Evidently, the highest density of intensive peaks in the IR spectra is observed for the all specimens. Both for the source TEG and for all specimens of functionalized TEG, the peaks corresponding to the impurities have been observed: a broad band corresponding to the vibrations of bounded $-\mathrm{OH}$ groups (water) near $3410 \mathrm{~cm}^{-1}$ and a peak at $2354 \mathrm{~cm}^{-1}$ corresponding to vibrations of carbon dioxide. As it follows from the figures, the IR spectra for both specimens contain the peak at $3750 \mathrm{~cm}^{-1}$, which corresponds to the valence vibrations of hydroxyl -OH groups. The absorption double peaks observed near
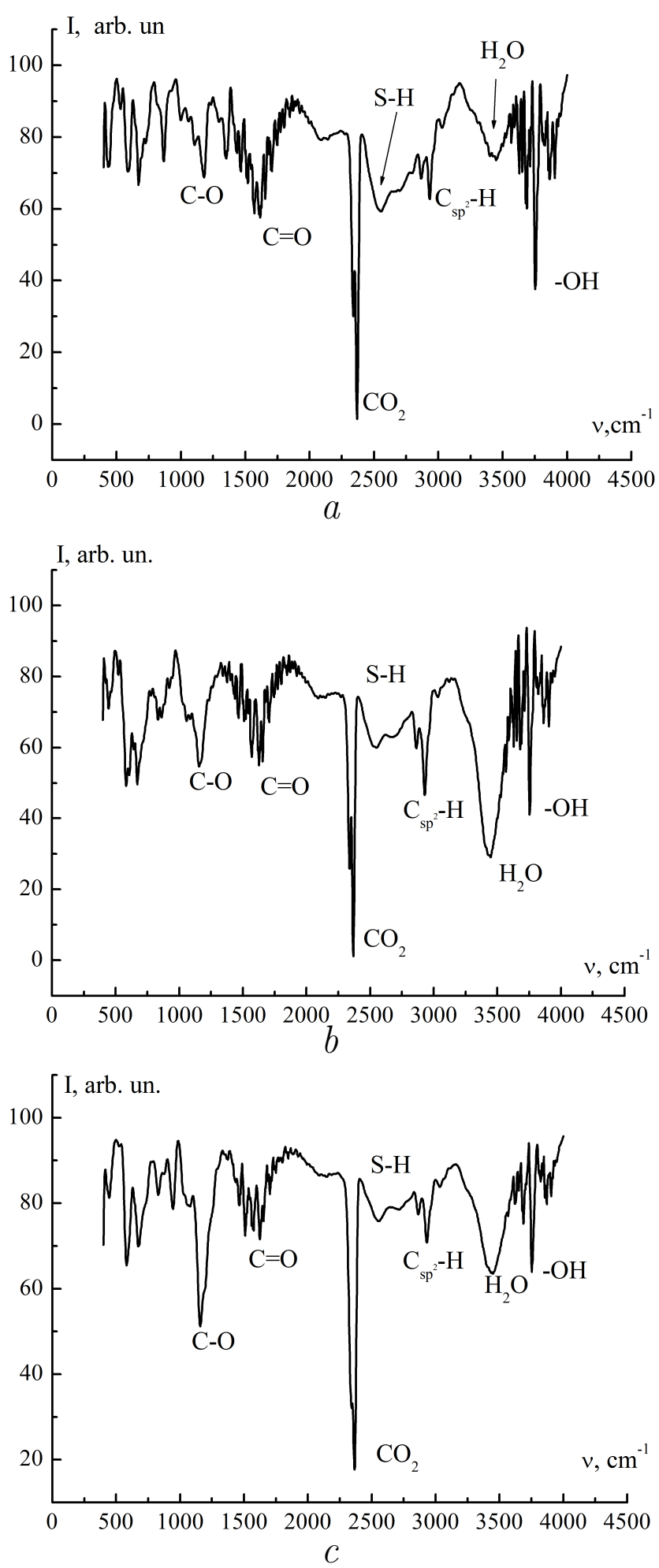

Fig. 2. The IR spectrum for specimen TEG functionalized with: a) solution of potassium permanganate in $20 \%$ sulfur acid; $b$ ) the mixture of nitric and sulfur acids with boiling; $c$ ) with the mixture of nitric and sulfur acid without boiling 
$3000 \mathrm{~cm}^{-1}$ for all specimens of functionalized TEG and for the source TEG are related to the hydrogen atoms bonded with $s p^{2}$ - and $s p^{3}$-hybridized carbon atoms. Valence vibrations of the $\mathrm{C}=\mathrm{O}$ double bond cause an intensive signal within the $1800-1650 \mathrm{~cm}^{-1}$ frequency range for all specimens of functionalized TEG. A precise position of the carbonyl absorption band in the spectrum depends on the nature of substitutions at $\mathrm{C}=\mathrm{O}$ carbonyl groups. The absorption band at $1560 \mathrm{~cm}^{-1}$ is caused by valence vibrations of multiple $\mathrm{C}=\mathrm{C}$ bonds. The intensive peaks corresponding to the valence vibrations of $\mathrm{C}=\mathrm{O}$ and $\mathrm{C}=\mathrm{C}$ groups are very close to each other and form a broad band. A band, which corresponds to the valence vibrations of a lactone group, is observed in the $1450 \mathrm{~cm}^{-1}$ frequency region. The spectrum region from $1300 \mathrm{~cm}^{-1}$ to $625 \mathrm{~cm}^{-1}$, known as the "dactylogram" region, contains absorption bands corresponding to vibrations of $\mathrm{C}-\mathrm{O}$ groups and to deformation vibrations of $\mathrm{C}_{s p^{2}}-\mathrm{H}$ and $\mathrm{C}=\mathrm{C}$ groups. A broad absorption band is observed at $2560 \mathrm{~cm}^{-1}$, which is absent at the IR spectrum for the source TEG. This band corresponds to $\mathrm{S}-\mathrm{H}$ valence vibrations and is related to the presence of the sulfur acid refuses in the functionalized TEG.

Thereby, the small amounts of all functional groups except hydroxyl ones were found in the source TEG. The relative intensity of the peak, which corresponds to the valence vibrations of the hydroxyl group, is maximal, as compared with the relative intensity of peaks, which correspond to the vibrations of all other functional groups for specimens 1 and 2. For specimen 3, the relative intensity of the $-\mathrm{OH}$ peak is practically equal to the relative intensity from carbonyl groups involved in the structure of carbon acid. For specimen 1, the relative intensity of the peaks corresponding to the vibrations of carbonyl groups involved in the structure of ketone and carboxyl groups is almost the same. For specimen 2, the intensity of the peak corresponding to the vibrations of $\mathrm{C}=\mathrm{O}$ groups involved in the structure of carboxyl groups is 1.7 times higher than that for the peak corresponding to the vibrations of carbonyl groups involved in the structure of ketone groups.

The ratios of the concentrations of functional groups on the TEG surface

Ratios of the concentrations of functional groups on the TEG surface

\begin{tabular}{c|c}
\hline Specimen & $-\mathrm{OH}: \mathrm{C}=\mathrm{O}$ (ketone) $\mathrm{C}=\mathrm{O}($ carboxyl $):$ lactone: $\mathrm{C}-\mathrm{O}$ \\
\hline 1 & $2.20: 1.59: 1.50: 1: 1$ \\
2 & $2.38: 1.06: 1.81: 1: 1.88$ \\
3 & $1.83:-1.67: 1: 3.33$ \\
\hline
\end{tabular}

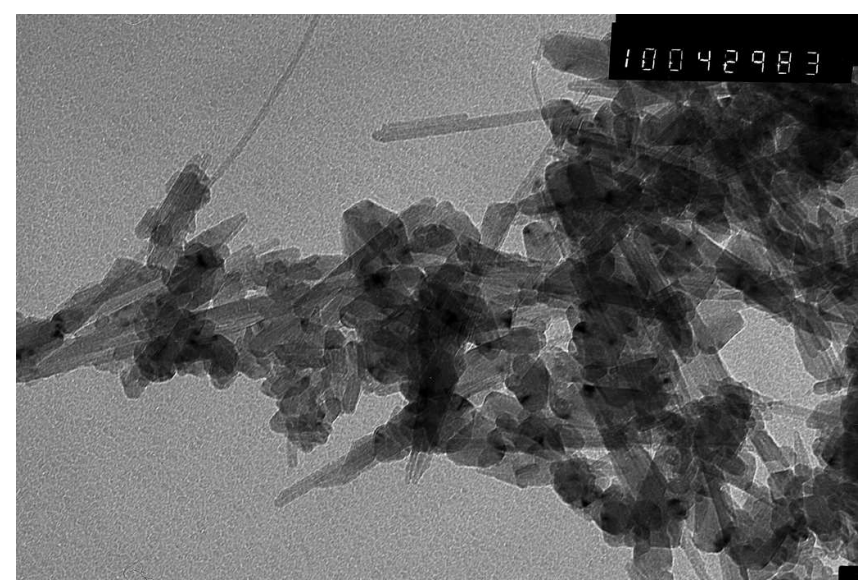

Fig. 3. TEM image of TEG particles functionalized by potassium permanganate solution in sulfur acid

$(-\mathrm{OH}: \mathrm{C}=\mathrm{O}($ ketone $): \mathrm{C}=\mathrm{O}($ carboxyl $):$ lactone: $\mathrm{C}-\mathrm{O})$ are listed in Table.

So, the performed IR spectroscopy studies of the specimens functionalized under different regimes evidence of the formation of the functional groups upon the treatment of TEG particles, whose quantity and concentration are determined by the method of functionalization and the type of a functionalizing agent. If strong oxidants (i.e., potassium permanganate) were used as a functionalizing substance, the concentration of all detected functional groups is the highest. Here, the highest concentration was observed for the hydroxyl group. If the mixture of sulfur and nitric acids was used as a functionalizing substance, the qualitative and quantitative compositions of functional groups on the TEG particle surface depend on the regime of functionalization (either with or without boiling). If TEG was functionalized with boiling in the mixture of acids, the highest concentration was observed for the hydroxyl group. If TEG was functionalized without boiling, the content of hydroxyl and carboxyl groups were almost the same.

Figure 3 presents a part of the TEM image of TEG particles functionalized by a potassium permanganate solution in sulfur acid.

Particles of the tetragonal shape or some fragments of the acicular shape with rounded edges $60 \mathrm{~nm}$ in length and 2 to $20 \mathrm{~nm}$ in width are observed. Parallel layers are clearly seen along the bigger size of each particle. These layers were identified as graphite layers. The particles are elongated along graphite layers, the lateral surfaces of particles, as well as the graphite layers, are rounded. The sizes of particles along the graphite layers are considerably higher those in the perpendicular direction. 


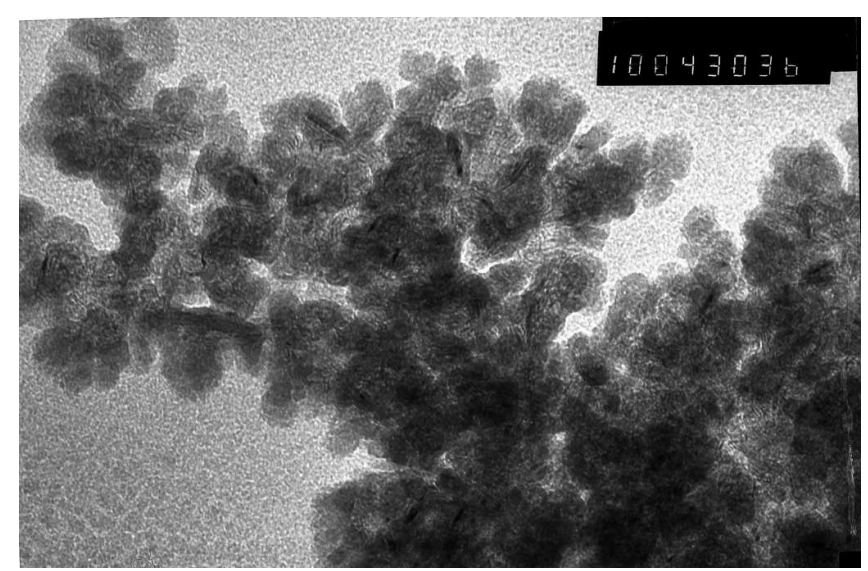

Fig. 4. TEM image of TEG particles functionalized with the mixture of nitric and sulfur acids, repeated dispersing time 1 hour

Figure 4 presents a part of the TEM image of TEG particles functionalized with a mixture of nitric and sulfur acids, repeated dispersing time $1 \mathrm{~h}$.

As is clearly seen, the separate rounded particles of irregular shape possessing lacerated "petal-shaped" edges 20-40 nm in size are observed. Graphite layers are recognized within the particles; however, they are spun and twisted along the perimeter rather than in parallel.

The presented data show that the structure of particles of functionalized graphite essentially depends on the type of a functionalizing agent. If potassium permanganate is used as a functionalizing agent, TEG particles are prolate along graphite layers, and their edges are rounded. The sizes of particles along graphite layers are considerably higher that those in the perpendicular direction. Particles are flat and undistorted, and the graphite layers are not twisted. Evidently, the destruction of the vermicular structure of the source TEG proceeds along graphite layers, i.e., the weak van der Waals bonds between graphite layers and within the edge defects of crystallites are broken. TEG particles functionalized by potassium permanganate consist of 4 to 10 flat graphite layers. So, the treatment of TEG by potassium permanganate leads to the formation of graphite structures containing less than 10 graphite layers, i.e., to the formation of graphene-like structures in graphite nanoparticles. Small-size particles $(1-5 \mathrm{~nm})$ containing a low amount of graphite layers are formed also in a case of the TEG functionalization by a mixture of nitric and sulfur acids with boiling. In contrast to specimen 1, the graphite layers in TEG functionalized according to this procedure are spun and twisted, rather than flat. The size of particles for the specimens under the TEG functionalization by a mixture of nitric and sulfur acids without boiling directly depends on the time of the repeated dispersing in a magnetic mixer. Under the low time of dispersing, the great-size particles with rough lateral surface are formed. The size of particles decreases, and its shape becomes more rounded, as the dispersing time increases.

\section{Conclusions}

So, the performed studies of the functionalized TEG revealed that the patterns of changes in the TEG structure depend on the type of a functionalized substance, functionalization method, and time dispersion. It is shown that using a strong oxidizer as a functionalized substance, which is a solution of potassium permanganate in sulfuric acid, leads to the rupture of the weak van der Waals connection between graphite layers and edge defects of crystallites, which causes the intense destruction of the worms-like TEG particle structure and splits it into separate round shape plates containing from 4 to 10 flat graphite layers. Thus, the TEG treatment by potassium permanganate leads to the formation of graphite structures, where the number of graphite layers is less than 10, i.e., to the formation of graphene-like structures - graphite nanoplates. Using the "soft" oxidants as functionalized substances leads to the slow process of destruction of the original worms-like TEG structure. Thus, under the TEG functionalization by a potassium permanganate solution, it is possible to achieve small sizes of TEG particles only by the chemical treatment. For other functionalizing inorganic substances, the small sizes of TEG particles can be achieved only through the long-time dispersion of a TEG powder.

The work has been carried out according to Project N4908 of the Science and Technology Center of Ukraine.

1. M.S.P. Shaffer, X. Fan, and A.H. Windle, Carbon 36, 1603 (1998).

2. J. Yun, J. S. Im, Y.-S. Lee, and H.-I. Kim, Eur. Polym. J. 46, 900 (2010).

3. Q. Li, Q.Z. Xue, X.L. Gao, and Q.B. Zheng, Polym. Lett. 3, 769 (2009).

4. W. Shuguang, L. Yanhui, G. Xiaoyan, Z. Huazhang, L. Zhaokun, X. Cailu, and W. Dehai, Chin. Sci. Bull. 48, 441 (2003).

5. L. Moiseeva, S. Kireev, and A. Evseev, Nanoindustry 16 (2008), (in Russian).

6. R. Andrews and M.C. Weisenberger, Solid State and Mat. Sci. 8, 31 (2004). 
7. S.H. Jeong, J-H Ko, J.-P. Park, and W. Park, J. Amer. Chem. Soc. 126, 15982 (2004).

8. M. Olek, Carbon Nanotube Composites - Mechanical, Electrical and Optical Properties, Dissertation, (Rheinischen Friedrich-Wilhelms-Universitat Bonn, Bonn, 2006), http://hss.ulb.uni-bonn.de/dissonline elektronisch publiziert.

9. D.A. Usanov, A.V. Skripal, and A.V. Romanov, Techn. Phys. 81(1), 106 (2011) (in Russian).

10. A. Bassil, P. Puech, G. Landa, W. Bacsa et al., J. of Appl. Phys. 97, 034303 (2005).

11. Q. Li, M. Zaiser, and V. Koutsos, Phys. Stat. Sol. (a) 201(13), 89 (2004).

12. V.A. Krutikov, A.A. Didik, G.I. Yakovlev et al., ISJAEE No. 4, 36 (2005) (in Russian).

13. X. Xu, M.M. Thwe, C. Shearwood, and K. Liao, Appl. Phys. Lett. 81(15), 2833 (2002).

Received 23.09.11

\section{ХАРАКТЕРИСТИКА НАНОДИСПЕРСНОГО ГРАФІТУ}

Ю.С. Перец, І.В. Овсієнко, Л.Л. Вовченко, Л.Ю. Мачуй, О.А. Брусіловеи, І.П. Пундик

Р е з ю м е

Роботу присвячено проблемам взаємозв'язків між методами функціоналізації та характеру розподілу функціональних груп на поверхні нанографітових пластин. Функціоналізацію початкового терморозширеного графіту (ТРГ) проводили з використанням неорганічних реагентів, таких як розчин $\mathrm{KMnO}_{4}$ у сірчаній кислоті і суміші сірчаної та азотної кислот і з різною тривалістю першого і повторного диспергування у магнітній мішалці. Кількісний та якісний склад функціональних груп на поверхні нанографітових пластин визначено методом ІЧ-спектроскопії. Як з'ясовується з детальних досліджень структури функціоналізованого графіту, функціоналізація приводить до руйнування початкової структури ТРГ і скорочення розміру частинок ТРГ до декількох нанометрів. 